\title{
TER DEFICIÊNCIA É SER SUPER-HUMANO? UMA ANÁLISE DISCURSIVA DE UM FILME PUBLICITÁRIO PARA AS PARALIMPÍADAS RIO 2016, “WE'RE THE SUPERHUMANS"
}

\author{
CLEVISVALDO PINHEIRO LIMA ${ }^{1}$
}

\author{
Instituto de Estudos da Linguagem \\ Universidade Estadual de Campinas \\ R. Sérgio Buarque de Holanda, 571 - Cidade Universitária, Campinas - SP, 13083-859
}

\author{
klevislima@hotmail.com
}

\begin{abstract}
Resumo. Os eventos esportivos tornaram-se, a partir do século $X X$, verdadeiros espetáculos, objetos de festa, de celebração coletiva. O esporte paralímpico, criado, inicialmente, enquanto ferramenta terapêutica, foi, aos poucos, inserindo-se nesse contexto, a ponto de atualmente ser o segundo maior evento esportivo do mundo. Nesse sentido, neste artigo, com base no dispositivo teórico-analítico da Análise de Discurso materialista, procuramos, a partir da análise do filme publicitário We're The Superhumans, produzido pela rede de televisão britânica Channel 4, compreender o modo como o atleta com deficiência é significado no/pelo filme, e os efeitos de sentido que são produzidos acerca da pessoa com deficiência.
\end{abstract}

Palavras-chave: paralimpíadas; deficiência; acessibilidade; Análise de Discurso.

\begin{abstract}
Sporting events became, from the twentieth century, real spectacles, objects of celebration, collective celebration. Paralympic sport, initially created as a therapeutic tool, was gradually inserted in this context to the point of being currently the second largest sporting event in the world. In this sense, in this article, starting from the theoretical-analytical device of Materialistic Discourse Analysis, we seek from the analysis of the advertising film "We're The Superhumans", produced by the British television channel Channel 4, to understand the way the athlete with Disability is signified in / by the film and the sense effects that are produced about the disabled person.
\end{abstract}

Keywords: paralympics; disability; accessibility; Discourse Analysis.

\footnotetext{
${ }^{1}$ Doutorando em Linguística pela Universidade Estadual de Campinas - UNICAMP. Mestre em Letras pela Universidade Federal do Piauí - UFPI. Graduado em Geografia pela Universidade Estadual do Piauí UESPI. Professor Assistente da Universidade Federal do Piauí - UFPI. Membro do projeto de pesquisa Imagens da Cidade: Discurso e Produção de Conhecimento (LABEURB/UNICAMP/FAPESP)
} 
não se nasce uma pessoa com deficiência (o que isto significa?) torna-se pessoa com deficiência em um processo que envolve o indivíduo, seu assujeitamento, sua individuação pelo Estado, as imagens que o envolvem socialmente, e o modo como ele se identifica e é identificado, significado etc. (ORLANDI, 2015)

\section{INTRODUÇÃO}

Os jogos paralímpicos surgiram na Inglaterra, a partir da segunda metade do século XX, sendo reputado como o segundo maior evento esportivo do mundo, perdendo apenas para os jogos olímpicos. A princípio, eram concebidos como práticas de reabilitação destinada a veteranos de guerra e civis afetados pelos combates da II Guerra Mundial. O sucesso alcançado nesse processo permitiu que uma atividade inicialmente de cunho terapêutico se tornasse um evento esportivo de alto rendimento, fazendo das paralimpíadas o expoente máximo do desporto adaptado, alcançando um número crescente tanto de países quanto de atletas participantes em cada edição (FIGUEIREDO, 2010).

Consoante Vigarello (2017), levando em consideração, por um lado, que o esporte fabrica, acima de tudo, "heróis", padrões a serem admirados por suas performances, suas habilidades, seus desempenhos e pelo seu corpo, em geral, musculosos e atléticos aspecto que os configura como representantes e símbolos da sociedade -, e por outro lado, que os corpos com deficiência são, segundo Hashiguti (2016), invisíveis e esquecidos nas práticas discursivas, cuja identidade é reduzida a um aspecto de seu corpo, construída "por um 'a mais' ou um 'a menos' em relação à estética humana" (BARBAI, 2016, p. 39), estabelecemos como princípio norteador desta análise os seguintes questionamentos: como o atleta com deficiência é significado no/pelo filme publicitário? Que efeitos de sentido são produzidos? O filme rompe ou fortalece os estereótipos que figuram no imaginário social acerca da pessoa com deficiência?

O material que fundamenta a presente análise, desenvolvido sob a perspectiva teórico-metodológica da análise de discurso materialista, consiste de um filme publicitário produzido pela rede de televisão britânica Channel $4,{ }^{2}$ com vistas a promover os Jogos Paralímpicos de Verão de 2016, entre os dias 7 e 18 de setembro, na cidade do Rio de Janeiro, no Brasil. A emissora foi a detentora oficial dos direitos de transmissão na Grã-Bretanha. O filme, intitulado We're the superhumans, foi disponibilizado no canal oficial da emissora na rede social You Tube. De acordo com a Wikipedia, o filme venceu, em 2017, o Cannes Lions International Festival of Creativity, que representa o maior evento da indústria da publicidade e comunicação criativa.

\section{PRIMADO AO GESTO DE DESCRIÇÃO}

$\mathrm{Na}$ acepção de Lagazzi (2013), filmes e documentários constituem um significativo repertório de formulações para análise. Coadunando a referida autora, a imbricação entre a materialidade verbal e a materialidade visual - tendo em vista, ainda,

\footnotetext{
${ }^{2}$ Link do vídeo: https://www.youtube.com/watch?v=IocLkk3aYlk
} 
a materialidade sonora na composição fílmica - possibilitam gestos analíticos que ratificam a robustez do dispositivo teórico-analítico da Análise de Discurso materialista, uma disciplina que trabalha com a contradição; que se constrói no/pelo entremeio; que olha a partir das diferenças e não da unidade; que compreende que os sentidos não se fecham, não são evidentes, que sempre podem ser outros, embora não qualquer um.

Para tanto, é preciso que o analista dê, no entendimento de Pêcheux (2015), primazia aos gestos de descrição das materialidades discursivas, entendendo que a análise de discurso é, antes de tudo, análise, e que "é somente ao dar lugar à descrição pelo exercício parafrástico que a evidência do conteúdo será relativizada e o analista poderá dar consequência ao movimento da interpretação para compreendê-lo em seus préconstruídos" (LAGAZZI, 2015, p. 86). Dessa forma, ao pôr em funcionamento o dispositivo teórico-analítico por um batimento entre descrição e interpretação, o analista poderá compreender o funcionamento e os efeitos de sentidos produzidos em seu material de análise.

Como mencionamos, We're The Superhumans é um filme publicitário que foi criado para a promoção dos jogos paralímpicos de 2016. Com uma duração de 3'13', disponibiliza a opção de legenda oculta (closed caption), em inglês, e conta com a participação de atletas paralímpicos de diferentes modalidades esportivas da GrãBretanha, além de um atleta de salto em altura da Ucrânia e outro de natação da Holanda. ${ }^{3}$ O clipe tem como pano de fundo a música Yes I can, de Sammy Davis Jr., tocada por uma banda integrada por músicos com diferentes tipos de deficiências e cantada por um cadeirante, retratando diferentes situações vividas por atletas e não atletas com deficiência.

No que concerne à sua materialidade digital, importa salientar que até o dia 9 de setembro, o vídeo havia atingido 9.522.226 visualizações, 57 mil likes, 1,2 mil dislikes, e, contrariamente a outros vídeos disponíveis no canal oficial da emissora Channel 4, a caixa de comentários do vídeo em epígrafe está desativada, sendo possível apenas compartilhar, e clicar em gostei (like) ou não gostei (dislike).

O filme inicia-se com a câmera fechada no tambor da bateria e vai, paulatinamente, abrindo para mostrar que as baquetas estão sendo manejadas com os pés e que quem as manuseia é um baterista sem os braços. Em seguida, a movimentação da câmera provoca um efeito de apresentação dos músicos da banda, destacando o fato de que ela é toda composta por pessoas com deficiência. Além do baterista sem ambos os braços, é possível perceber outros instrumentistas com outras deficiências: sem um dos braços; em cadeira de rodas; com síndrome de Down; usando próteses de braço; além de uma pianista cega. Ao iniciar a música Yes I can, suddenly, yes I can ${ }^{4}$ o cantor desce uma rampa e aparece em meio a uma corrida, em cadeira de rodas, enquanto canta I'm afraid to go on, has turn into Yes, I can.

\footnotetext{
${ }^{3}$ Informações disponíveis na própria descrição do vídeo.

${ }^{4}$ Sim eu posso, de repente, sim eu posso (tradução nossa).
} 

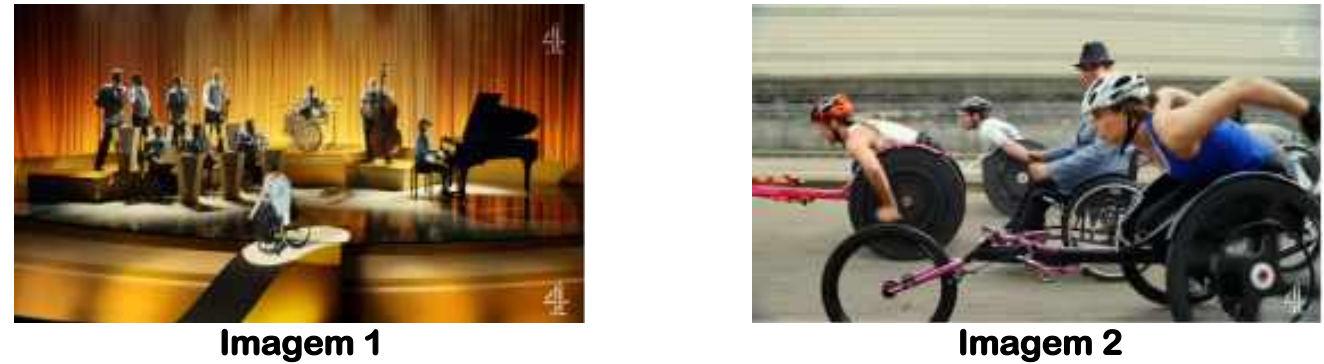

Na sequência, enquanto ouvimos o trecho Take a look what do you see?, atletas paralímpicos de diferentes modalidades e com diferentes deficiências são destacados, como ilustrado nas Figuras 3 a 6.
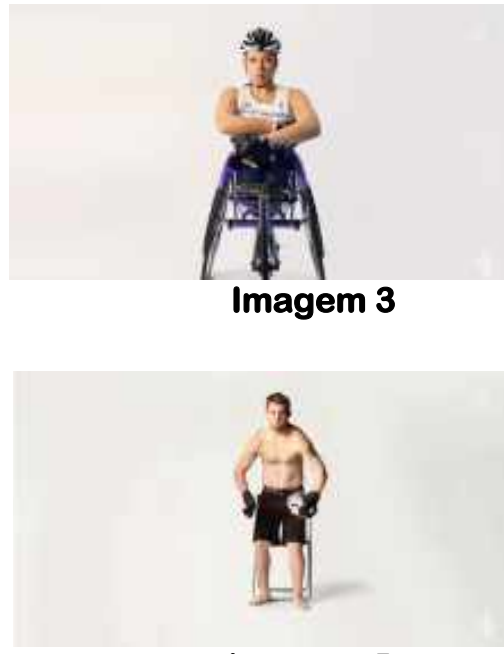

Imagem 5

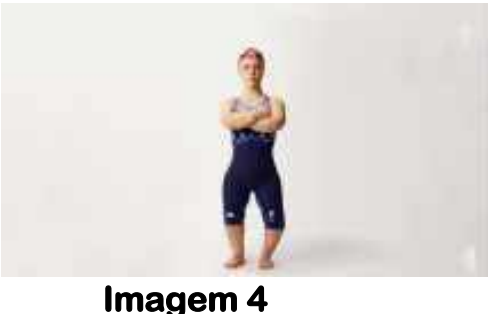

Imagem 4

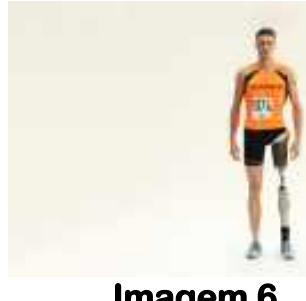

Imagem 6

Após ser apresentado, há um corte, e o último atleta (Imagem 6) aparece, já em um estádio lotado, pronto para realizar uma prova de salto em altura, o que executa com êxito. Enquanto isso, o trecho da música tocado é $A$ hundred and thirty three pounds of confidence $m e .^{5}$

Na sequência, enquanto a materialidade verbal apreendida é Got the feeling I can do anything, yes I can. Something that sings im my blood is telling me, yes I can, ${ }^{6}$ o filme passa a mostrar, em sua materialidade visual, não atletas sem braços desempenhando diferentes atividades cotidianas, como trabalhar, alimentar-se, cuidar de um bebê, ilustradas nas Imagens 7 a 9.

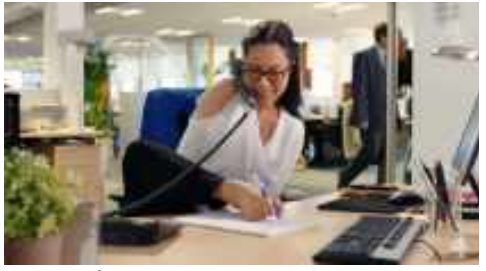

Imagem 7

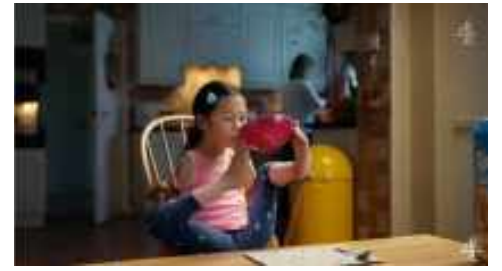

Imagem 8

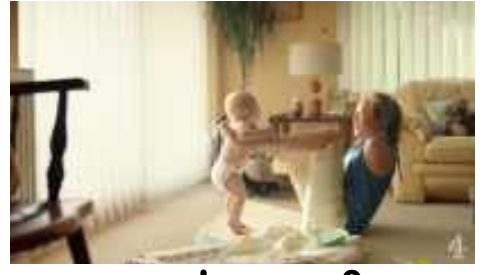

Imagem 9

\footnotetext{
${ }^{5}$ Cento e trinta e três libras de confiança em mim (tradução nossa).

${ }^{6}$ Tenho a sensação de que posso fazer qualquer coisa, sim eu posso. Algo que canta no meu sangue está me dizendo, sim eu posso (tradução nossa).
} 
Nessa mesma sequência, um piloto de carros de corrida do tipo nascar (um atleta, embora de um esporte sem vínculo com as paralimpíadas) faz manobras em torno da banda responsável pela música do filme, em uma área aberta, como mostrado nas Imagens 10 e 11 , abaixo.

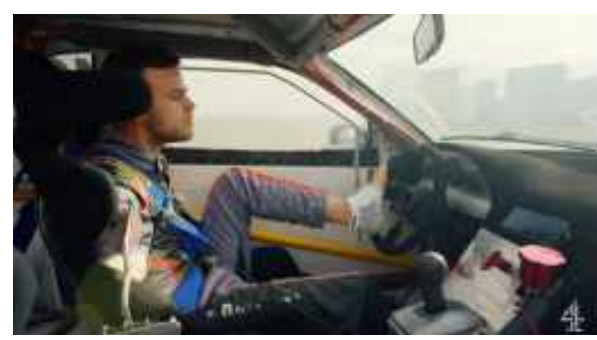

Imagem 10

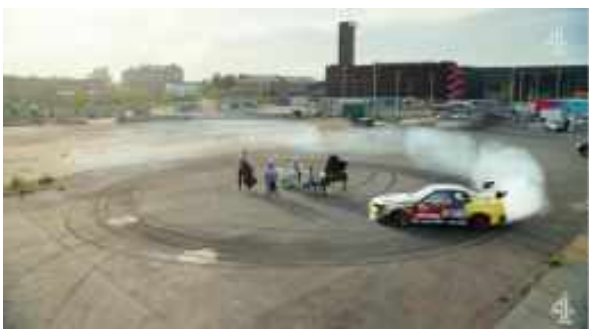

Imagem 11

Em seguida, o filme mostra um salão de festas onde homens cadeirantes dançam com mulheres sem deficiência, no que parece ser um concurso de danças, porquanto trazem números de identificação em suas cadeiras. Enquanto isso, o trecho cantado é $I$ was just born today. ${ }^{7}$

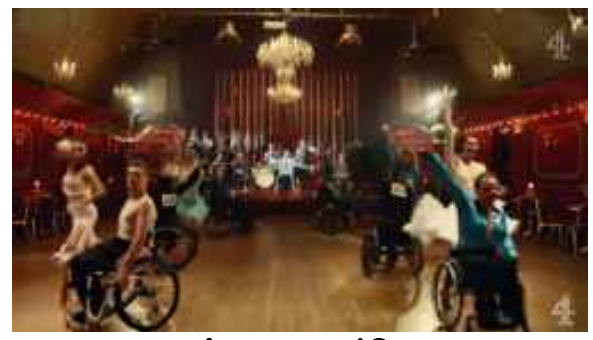

Imagem 12

Um dos cadeirantes, então, é mostrado saindo da pista de dança (a câmera posiciona-se atrás dele, mostrando as suas costas), e rapidamente uma sequência de outras cenas são sobrepostas, mostrando, a partir da mesma perspectiva da câmera, outros cadeirantes em diferentes situações: entrando em uma sala de reuniões para, provavelmente, presidi-la (todos se levantam quando ele entra e, além disso, o lugar que ocupa é o da ponta da mesa, imaginariamente ocupado por aqueles que exercem maior autoridade); cruzando a linha de chegada de uma competição de atletismo em cadeira de rodas; fazendo compras no supermercado; jogando basquete em cadeira de rodas. Simultaneamente, o trecho I can go all the way. Yes I $\mathrm{can}^{8}$ é tocado.

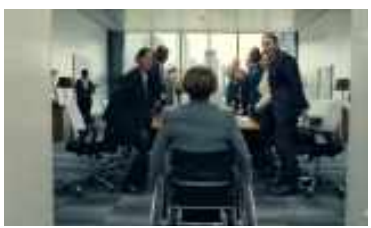

Imagem 13

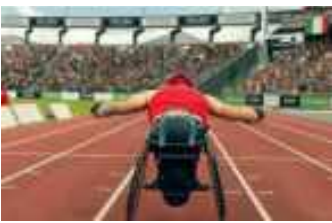

Imagem 14

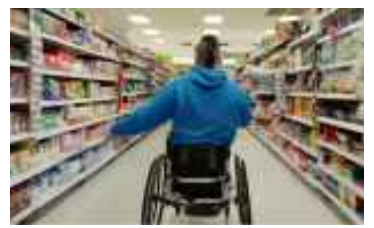

Imagem 15

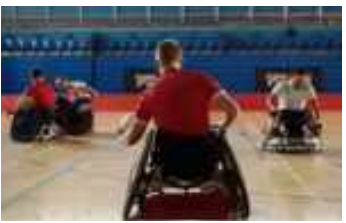

Imagem 16

\footnotetext{
${ }^{7}$ Eu nasci hoje (tradução nossa).

${ }^{8}$ Eu posso ir a qualquer lugar (tradução nossa).
} 
Ao tempo em que canta o trecho yes, I can desta sequência, o cantor aparece atravessando a quadra em um jogo de basquete (Imagem 16), e ao cruzar uma cortina localizada no fim da quadra, encontra-se novamente em um salão de festas ocupado por dançarinos de sapateado - ambos sem a perna direita, que é substituída por próteses. Nesse momento, ouve-se apenas o som do piano, das batidas dos sapatos e das próteses no tablado. Dos dançarinos, a câmera corta para o pianista, que também é portador de deficiência - que possui apenas uma pequena parte de ambos os braços. Sobrelevamos, ainda, o fato de que este é o único trecho no filme em que a cena se passa em preto e branco, como se pode observar nas Imagens 17 e 18.

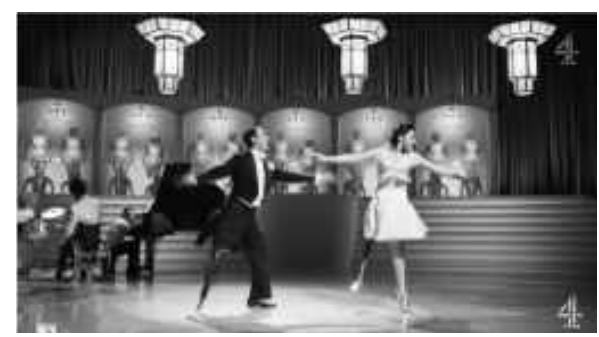

Imagem 17

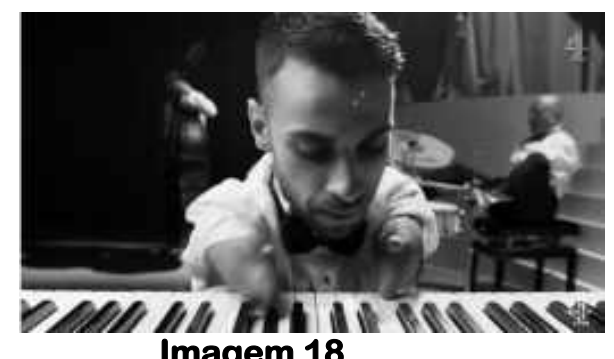

Imagem 18

$\mathrm{Na}$ mesma sequência, há um momento em que os dançarinos passam a dançar individualmente, rodeados por próteses de pernas de diferentes tamanhos e modelos, os quais se movem e dançam, ainda que não tenham um usuário, como visto nas Imagens 19 e 20 .

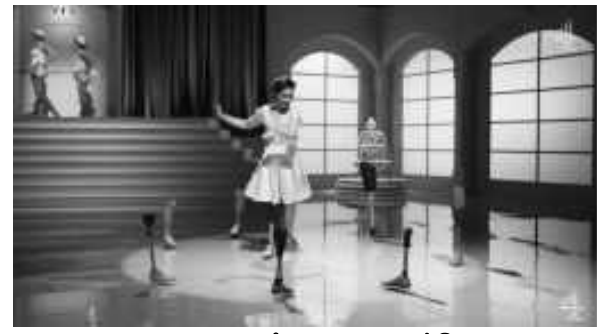

Imagem 19

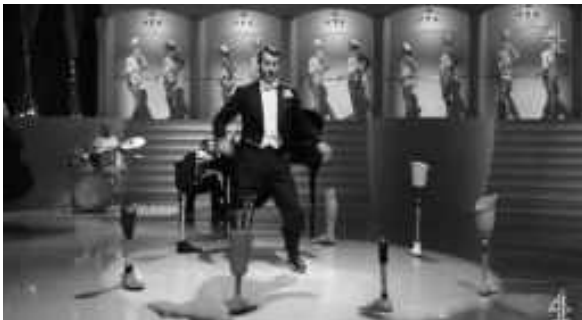

Imagem 20

Do solo do piano, com um cenário em preto e branco, passa-se a um solo, agora de guitarra. A passagem de um para o outro, que também indica a mudança de cenário, ocorre no momento em que o cantor do clipe coloca um capacete, desce um lance de escadas em sua cadeira de rodas e joga-se em uma janela de vidro à sua frente, estilhaçando-a.

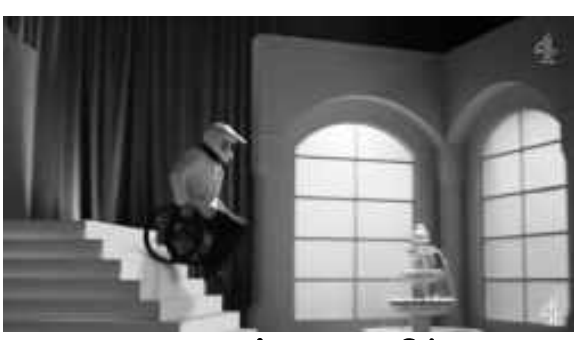

Imagem 21

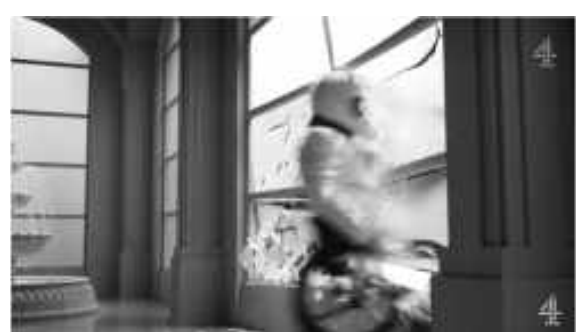

Imagem 22

Entre um solo e outro temos, além do barulho do estilhaçar da janela, o estampido de um tiro de partida, onde assistimos, ao som da guitarra, à largada de modalidades 
esportivas, como a natação e o atletismo, seguido de uma sequência de imagens de diferentes esportes paralímpicos, como: o basquete em cadeira de rodas; a esgrima em cadeira de rodas; e o futebol de cegos (aqui, um atleta da modalidade aparece pedindo silêncio, e a prova é mostrada sem qualquer som, além daquele produzido pela bola dessa modalidade).

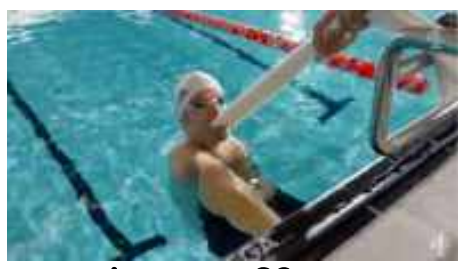

Imagem 23

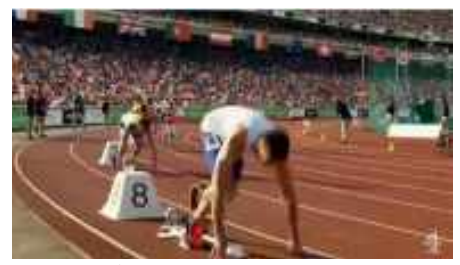

Imagem 24

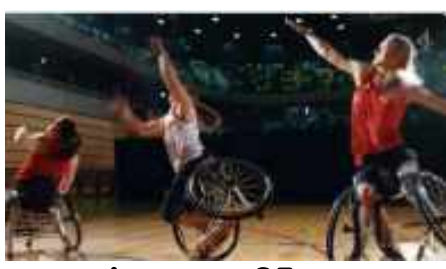

Imagem 25

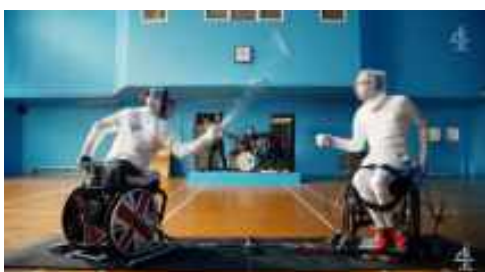

Imagem 26

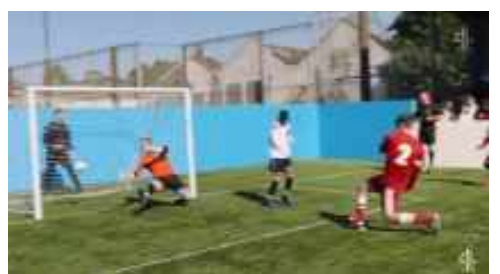

Imagem 27

Após um gol ter sido marcado, e em meio aos gritos de comemoração da torcida, a banda, posicionada na arquibancada do jogo de futebol para cegos, retoma a música e passa a cantar Yes, I can. ${ }^{9}$ Essa frase é repetida oito vezes, mas diferentemente do que ocorria durante o filme, ela passa a ser cantada não apenas pela banda, mas também pelos atletas, enquanto praticam suas respectivas modalidades: uma piloto de avião sem braços, enquanto está pilotando sua aeronave; um jovem com síndrome de Down, que aparece em uma foto segurando um diploma de formatura. Nessa sequência fílmica surge, inclusive, a imagem de uma mulher abastecendo o seu veículo, como retratam as imagens 28 a 30 , abaixo.

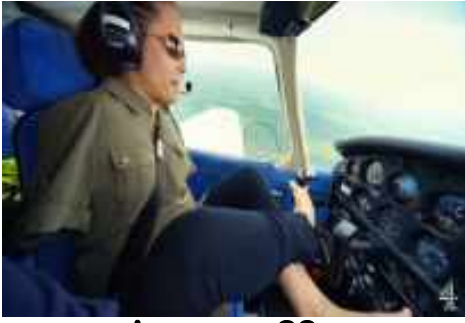

Imagem 28

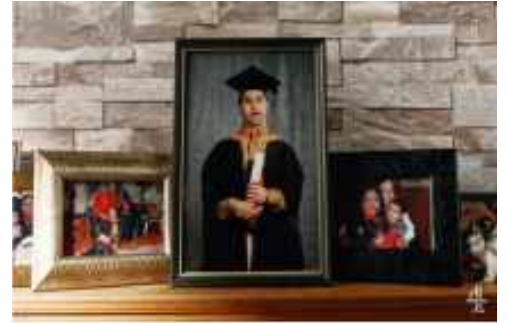

Imagem 29

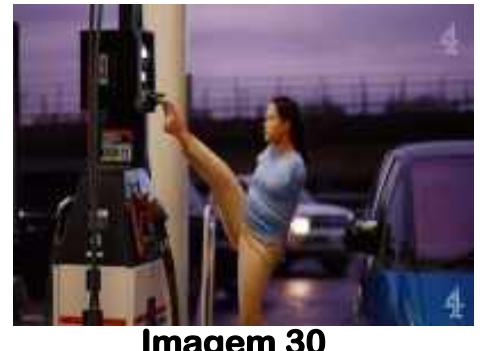

Imagem 30

Contrapondo-se a essa sequência de Yes, I can, cantada inclusive em língua de sinais britânica, mostra-se, a partir de uma interrupção na música, uma cena em que um senhor, em uma escola (nesse instante, alguém de mochila passa em frente à câmera, ouve-se o som de uma sirene e o jovem está vestindo um uniforme escolar), diz a um jovem cadeirante: No. You, Can't. ${ }^{10}$

\footnotetext{
${ }^{9} \mathrm{Sim}$, eu posso (tradução nossa).

${ }^{10}$ Não, você não pode (tradução nossa).
} 


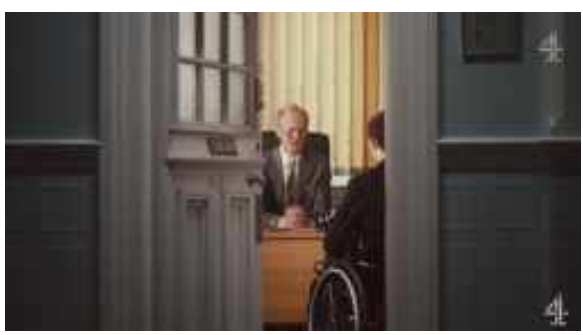

Imagem 31

Na porta da sala, há uma placa onde se lê: careers (carreira, profissão). Ao ouvir a resposta, o jovem olha para a câmera e a imagem corta para um jogador de basquete em uma cadeira de rodas. Este, aos gritos, diz: Yes, I can. A música, então, volta a tocar, com o trecho Are you ready? I can climb Everest. Yes I can. I can fight there all night and never rest. Yes I can. Durante esse excerto, vemos um jovem que não tem uma das mãos fazendo escalada em uma parede; em seguida, outros atletas praticando esportes de luta, como boxe, karatê e judô.

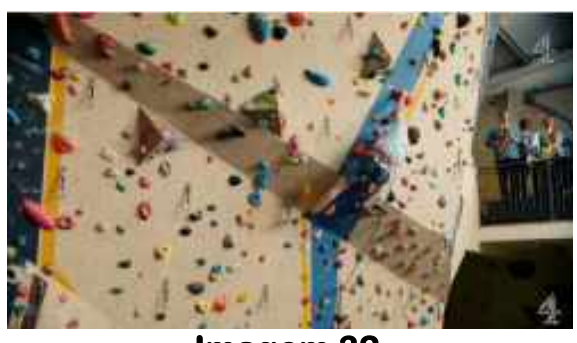

Imagem 32

Na passagem I was just born today. I can go all the way, aparecem crianças em diferentes cenários: brincando com sua prótese de braço colorida; jogando futebol com sua prótese de pena; brincando em um pula-pula; e assistindo a uma aula, como verificamos nas Imagens 33 a 35, a seguir.

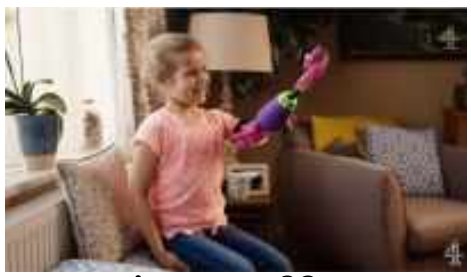

Imagem 33

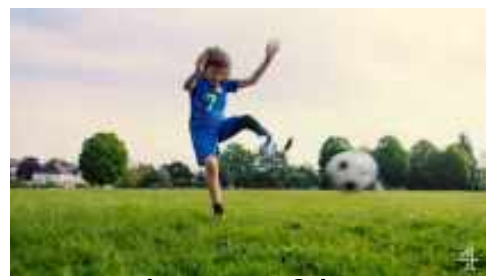

Imagem 34

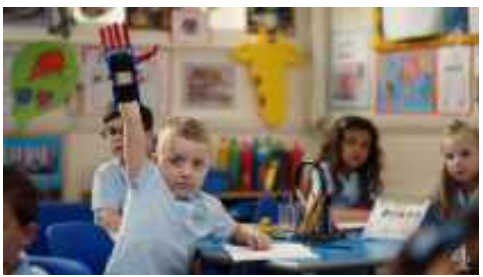

Imagem 35

Finalmente, o clipe é encerrado com um prolongado canto de Yes, I can, enquanto contemplamos o salto de um cadeirante em uma mega rampa, intercalado com a imagem de um jovem usando uma camisa estampando a bandeira do Brasil, escovando os dentes. Encerrando, aparece a frase WE'RE THE SUPERHUMANS, como ilustram as Imagens 36 a 38 . 


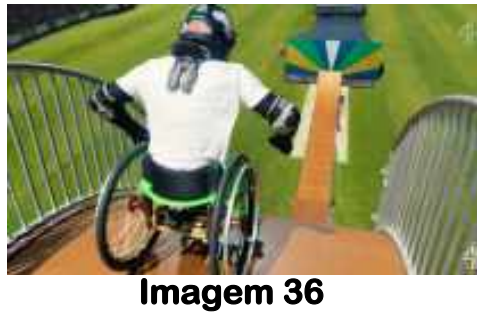

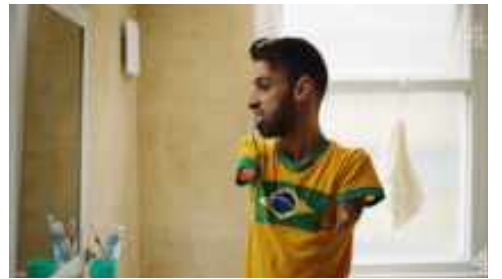

Imagem 37

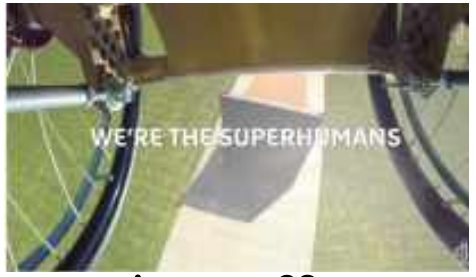

Imagem 38

Corroborando Pêcheux (2015), depreendemos que a descrição e a interpretação não representam fases sucessivas, mas de alternância ou batimento, e que o que interessa ao analista de discurso são os pontos onde afloram "a discursividade em seu real contraditório: lugar de tensão entre o mesmo e o diferente, dispersão do sujeito e do sentido" (ORLANDI, 2012, p. 12), que se manifestam materialmente no elemento analisado, daí porque procuraremos agora compreender os efeitos de sentidos produzidos pelo vídeo.

Assim como Lagazzi (2015), a análise ora proposta se dará pela remissão de uma materialidade significante a outra, na incompletude e na falha que as constitui, para que os efeitos produzidos pelo vídeo possam ser compreendidos no interior do funcionamento discursivo que organiza sua interpretação. Para tanto, tomaremos como ponto de entrada inicial a frase final do vídeo, que também é o título que o designa: We're superhumans.

\section{“WE'RE SUPERHUMANS"}

No filme, vemos vários atletas e não atletas com diversos tipos de deficiência realizando diferentes tipos de atividades: escovando os dentes (Imagem 37); competindo em uma prova paralímpica de esgrima (Imagem 26); pilotando um carro de corrida (Imagem 10) etc. Isso levou-nos, preliminarmente, a questionar: a quem o título do filme se refere? Quem são os "super-humanos"? são os atletas paralímpicos? Os não atletas, mas que realizam atividades que muitos não conseguiriam (independentemente de serem ou não deficientes), como pilotar um avião (Imagem 28) e saltar de uma mega rampa (Imagem 36)? Ou seriam aquelas pessoas que mesmo com deficiências conseguem realizar com autonomia atividades rotineiras, como trabalhar (Imagem 7); alimentar-se (Imagem 8); e fazer compras (Imagem 15)? Ou seriam todos eles?

Com o intuito de propormos uma des-superficialização do enunciado We're The Superhumans, para apreender os efeitos de sentidos que ele produz, e como o interdiscurso nele se inscreve, recorremos ao uso de paráfrases, um procedimento analítico que consiste em produzir diferentes possibilidades de formulação, buscando indícios, marcas linguístico-discursivas, alusivas ao processo de produção de sentidos.

Pelo uso de paráfrases, podemos observar, "a partir do contraste de formulações remetidas à sua exterioridade constitutiva, que efeitos são provocados pelo enunciado acima considerando os sentidos que se mantêm na base do dizível e os que se deslocam, ou seja, produzem outros sentidos, a polissemia" (COSTA, 2014, p. 106).

Dessa forma, na busca por paráfrases plausíveis para o enunciado We're The Superhumans (Nós somos os super-humanos), temos: 
1. Nós somos os super-humanos (We're the superhumans $\left.{ }^{11}\right)$.

1.1. Nós somos os deficientes.

1.2. Nós somos os super-humanos porque somos deficientes.

1.3. Nós somos os deficientes, por isso, somos super-humanos.

Partindo do princípio de que, como aduz Pêcheux (2014, p. 146), as palavras, expressões e proposições não são transparentes, embora pareçam ser, não existe um sentido fixado, a priori, mas "determinado pelas posições ideológicas que estão em jogo no processo sócio-histórico no qual as palavras, expressões e proposições são produzidas", ou seja, compreendendo que é a ideologia quem produz o efeito de evidência e de transparência das palavras. Nesse sentido, considerando as derivações possíveis para o enunciado Nós somos os super-humanos, nas condições de produção dadas, vislumbramos em funcionamento tanto um sentido estereotipado da deficiência quanto da segregação.

Costa (2014), ao perscrutar o funcionamento discursivo de uma campanha da Secretaria Especial dos Direitos Humanos pela Inclusão de Pessoas com Deficiência, desvela que há discursos que se apresentam como de inclusão, mas que discursivamente funcionam ratificando a exclusão.

A propósito, Figueiredo (2010) afirma que a mídia, ao tratar sobre as pessoas com deficiência, mesmo os atletas paralímpicos, o faz, em geral, de forma irreal e estereotipada. Aliás, é nesse contexto que vemos assumir o enunciado We're the superhumans.

As paráfrases explicitam a filiação desse enunciado a um dizer que toma as pessoas com deficiência como aquelas que não são iguais, que não podem ser, que são diferentes. ${ }^{12}$ Não há uma ruptura com os discursos de segregação e exclusão pelos quais os sujeitos com deficiência foram (são) significados historicamente. Há, ao contrário, a manutenção de definições pré-construídas sobre os deficientes como super-heróis, por "enfrentarem" e "superarem" cotidianamente os obstáculos impostos por sua deficiência, ainda que se trate de atletas de alta performance, como é o caso dos paralímpicos, tendo em vista que o foco do filme não está no desempenho deles, mas em sua deficiência, em seu corpo, como procuraremos evidenciar.

Em um texto que aborda a questão das minorias, Orlandi (2014, p. 32) assente que não podemos as ponderar como "um sujeito coletivo absolutamente idêntico a si mesmo e numericamente definido". Destarte, a referida autora assevera que a noção de diferença não pode ser domesticada, visto que os sentidos circulam e a relação com a alteridade não é direta, nem clara, nem unívoca. A noção de diferença, para ela, define-se no processo de constituição de cada sujeito, pela ideologia e pelo modo como este é individualizado pelo Estado, em uma sociedade capitalista.

Outrossim, Costa (2014) reconhece que em uma sociedade capitalista, dividida e hierarquizada pela simbolização das relações de poder, não há espaços para as diferenças, para o sujeito tido por desigual, que fica de fora. Produz-se, contudo, pelo discurso de

\footnotetext{
${ }^{11}$ Tradução proposta pelo autor.

${ }^{12}$ Aqui significada não como pensa Orlandi (2015), mas como um a-menos, com a sua identidade reduzida a um aspecto de seu corpo.
} 
igualdade, como efeito de sentido, a ilusão de uma inclusão, de uma sociedade justa e igualitária, como se a sociedade capitalista fosse aquela da oportunidade, onde todos têm as mesmas chances, bastando ao sujeito saber aproveitá-las.

É esse funcionamento discursivo que também vemos acontecendo nesse filme. Ele tem como regularidade apreensível o fato de repetir exaustivamente a expressão Yes I $\operatorname{can}^{13}$, enquanto mostra sujeitos com diferentes tipos de deficiência realizando diferentes tipos de atividades, sejam esportivas ou cotidianas, reforçando o discurso do sujeito como único responsável pelo seu sucesso (ou fracasso), e produzindo como efeito a ideia de que os deficientes podem qualquer coisa (Yes, I can [...]): ingressar no mercado de trabalho (Imagem 7); ter autonomia (Imagens 8, 9, 15, 30 etc.); ser mãe (Imagem 9); ser um piloto de corrida (Imagem 10) ou de um avião (Imagem 28); ter uma graduação (Imagem 29); ser chefe de uma empresa (Imagem 13); enfim, ser feliz. E, ainda, que digam: No, you can't (Imagem 31); cabe a você (e somente a você) mostrar que Yes, I can [...] do anything, go all the way.

Orlandi (2016, p. 213) ressalta que faz parte da ideologia, no capitalismo, "a existência de formas de onipotência no chamado domínio pessoal em que a posição é 'se eu quiser, eu posso tudo' e essa posição aparece como se sustentando na vontade e na consciência. No sujeito como origem e dono de si". É por essa ilusão de transparência, tanto do sujeito quanto da sociedade, que os sujeitos com deficiência aparecem no filme. Nele, não há dificuldades, não há preconceitos, os atores são capazes de tudo, pois os obstáculos podem ser superados pela palavra de ordem: Yes, I can (Gee, I'm afraid to go on has turned into yes, I can).

No filme, o sujeito com deficiência é significado como aquele que pode fazer qualquer coisa (do anything), ir a qualquer lugar (go all the way), independentemente de qual seja sua deficiência. Não importa que não haja acessibilidade, pois Yes, I can - ao descer um lance de escadas em uma cadeira de rodas (Imagem 21); não interessa se o Estado investe ou não em políticas voltadas às pessoas com deficiência, pois não há necessidade, uma vez que suddenly, yes, $\mathrm{I} \mathrm{can}^{14}$ - ainda que seja necessário forçar a entrada (Imagem 22).

A música estruturada em primeira pessoa produz, como efeito, uma imbricação entre a letra e o próprio discurso das pessoas com deficiência, como se representasse a voz desses sujeitos. O trecho onde pessoas com deficiência realizando diferentes atividades, esportivas ou não, aparecem cantando junto com a banda o enunciado Yes, $I$ can, reforça a produção desse impacto.

A escritora e ativista pelos direitos das pessoas com deficiência, Penny Pepper (2019), ao comentar esse filme publicitário em um artigo publicado no jornal britânico The Guardian, declara que as pessoas com deficiência não são heróis, nem querem ser: são indivíduos que, assim como qualquer outro, querem ter seus direitos garantidos, e que "a transformação de atletas com deficiência em status sobre-humano pelo Canal 4 apenas aprofunda nossas feridas, infligidas por ataques contínuos em nossas vidas diárias." 15 A

\footnotetext{
${ }^{13} \mathrm{Sim}$, eu posso. Tradução nossa.

${ }^{14}$ De repente, eu posso. Tradução nossa.

15 "The hyping of disabled athletes into superhuman status by Channel 4 only deepens our wounds, inflicted by continual assaults on our daily lives" (Tradução nossa).
} 
ativista ressai em seu artigo que esse tipo de publicidade apenas aprofunda os estereótipos sobre as pessoas com deficiência, o que é revalidado por Figueiredo (2010), em sua pesquisa sobre a divulgação dada ao esporte paralímpico pela mídia.

Em uma perspectiva discursiva, diríamos, ancorados em Orlandi (2015, p. 197), que se trata de um filme que não produz acessibilidade, ou seja, não produz "uma mudança no modo de significar os indivíduos". A autora mostra, e aqui retomamos a epígrafe, que em uma posição onde levamos em conta não apenas o imaginário social, mas também as condições de produção dos sujeitos e dos sentidos, as pessoas não nascem com deficiência, elas tornam-se deficientes em um processo que envolve "o indivíduo, seu assujeitamento, sua individuação pelo Estado, as imagens que o envolvem socialmente, e o modo como ele se identifica e é identificado, significado, etc." (ORLANDI, 2015, p. 191) - como resultado de um longo processo em que este é falado e significado pela ideologia que o interpela e pelos discursos que o dizem.

Nesse sentido, ao expor as pessoas com deficiência como "os" super-humanos, corajosos, seja pela materialidade verbal (I can do anything; I can go all the way; I can climb Everest; I can fight here all night and never rest) ou pela materialidade visual (Imagens 10, 11, 21, 22, 28, 32, e 36), repete-se o imaginário social de deficiência como algo que deve ser superado, apagado; e do deficiente como aquele que deve fazer coisas extraordinárias para 'compensar' suas limitações. Dito de outra forma, o filme não permite que outros discursos circulem, além daqueles já estabilizados no imaginário social: de que os sujeitos com deficiência ganhem corpo no corpo social e ascendam a "sujeitos históricos com acessibilidade política aos seus modos de vida, as suas práticas significantes” (ORLANDI, 2015, p. 197), a sua existência social.

Barbai (2016) reforça que a nossa sociedade tem elevado o corpo com deficiência ao domínio da coisa, reduzindo a identidade dele ao conjunto de seus aspectos. Hashiguti (2016), por sua vez, abona que há, historicamente, corpos possíveis de serem vistos e corpos tornados (in)visíveis. Ao analisar uma campanha publicitária que traz corpos com deficiência como manequins em vitrines de lojas, a supracitada autora conclui que a campanha em questão produz como acontecimento uma resistência à regularização de sentidos acerca dos corpos das pessoas com deficiência, trazendo-os à visibilidade. Antes (in)visíveis, na/pela campanha transformam-se em corpos possíveis de serem vistos e significados como padrões de corporalidade.

No filme que ora examinamos, também há um convite à visibilidade dos corpos com deficiência, não apenas como um efeito, mas enquanto materialmente realizados (take a look, what do you see? ${ }^{16}$ ). Os efeitos de sentido produzidos, no entanto, diferem daqueles assinalados por Hashiguti (2016) em seu material. Enquanto traz o enunciado take a look, what do you see? (dê uma olhada, o que você vê?), o filme apresenta uma sequência de imagens de atletas paralímpicos, de diferentes modalidades esportivas e com múltiplos tipos de deficiência (Imagens 3, 4, 5, 6), enquadrados no centro do vídeo que, nessas cenas, não tem qualquer paisagem ao fundo (este é branco), dando ênfase ao corpo em exposição.

Embora apenas nessa cena o convite ao expectador para lançar o olhar ao corpo com deficiência tenha sido verbalmente materializado, essa é outra regularidade presente

${ }^{16}$ Dê uma olhada, o que você vê? Tradução nossa. 
em todo o filme. Os enquadramentos de câmera dados aos sujeitos do/no vídeo, sejam atletas, não atletas ou membros da banda, são feitos sempre dando evidência à deficiência e não à atividade praticada ou ao esporte realizado, o que atualiza, enquanto memória discursiva, o espetáculo do corpo, ocorrido no decorrer do século XX.

Para Courtine (2011), o século XX foi marcado, entre outros aspectos, pelas feiras de exibição de corpos anormais, diferentes, estranhos, mutilados, monstruosos. Os sujeitos detentores desses corpos "deixam de ser vistos segundo o seu sexo, sua idade, sua enfermidade ou sua raça: ficam todos confundidos na monstruosidade" (COURTINE, 2011, p. 259). Tais corpos, consoante o referido autor, tornaram-se objetos comerciais, fontes de lucro. Além disso, a exibição do anormal tem como propósito a propagação de uma norma corporal. Nas palavras do autor, "é a normalidade do corpo urbanizado do cidadão que o desfile dos estigmatizados diante da objetiva convida a reconhecer no espelho deformador do anormal" (COURTINE, 2011, p. 280).

Dessa forma, deduzimos que os atletas e os não atletas com deficiência, exibidos ao longo do filme We're The Superhumans, são significados não pelos feitos que realizam, pelos esportes que praticam, mas pelo corpo que possuem. É a dar visibilidade desse corpo que o expectador é convidado, e é o corpo significado pela falta que é olhado, compreendendo o olhar sob o mesmo prisma de Hashiguti (2015): como um gesto de interpretação que faz com que o corpo, ao ser olhado, signifique.

\section{CONSIDERAÇÕES FINAIS}

Os jogos olímpicos nasceram na Grécia antiga, por volta de 776 a.C., com um aspecto, ao mesmo tempo, religioso, político e esportivo. Foram abandonados no século II, após a invasão do Império Romano à Grécia, e retomados no fim do século XIX (GODOY, 2001). Seu acontecimento, enquanto espetáculo, no entanto, ocorreu em meados do século $\mathrm{XX}$, quando o esporte passou a ser tomado tanto como uma valorização da vida saudável quanto uma demonstração de progresso (VIGARELLO, 2011).

O supramencionado autor destaca, ainda, que enquanto espetáculo, os eventos esportivos tornaram-se, também, objetos de festa, de celebração coletiva, uma mistura de distensão, efervescência e mercado. É nessas condições de produção que nascem as paralimpíadas, pensadas, a princípio, não como esporte, mas como terapias às pessoas com deficiência. Todavia, à medida que o número de adeptos, países e modalidades praticadas foi aumentando, o evento passou a ser significado do ponto de vista esportivo, a ponto de tornar-se o segundo maior evento esportivo do mundo, perdendo apenas para as olimpíadas.

Por esse ângulo, assim como a imagem dos atletas olímpicos, a figura dos atletas paralímpicos torna-se possível de ser explorada, entre outros, pelas cadeias de televisão, a partir de filmes publicitários como o que exploramos. O filme intitulado We're The Superhumans foi produzido pela TV estatal britânica Channel 4 para a promoção dos Jogos Paralímpicos de 2016, que aconteceram no Rio de Janeiro.

Em sua superfície, denota um convite aos telespectadores britânicos para assistirem aos jogos que seriam transmitidos pela referida emissora naquele país. Para 
tanto, o filme mostra vários atletas paralímpicos da Grã-Bretanha e de outros países, entre outros não atletas, mas igualmente com deficiência, realizando diferentes tipos de atividade ao som da música Yes I Can, do cantor Sammy Davis Jr.

Não obstante, por meio do dispositivo teórico da análise de discurso materialista, em um processo de des-superficialização do filme, foi possível perceber a produção de efeitos de sentido para além de uma divulgação esportiva. O esporte foi, como procuramos demonstrar, uma temática coadjuvante no filme, que produziu uma repetição estabilizada no/pelo imaginário social da pessoa com deficiência como aquela que deve ser admirada e aplaudida por conseguir realizar com autonomia atividades rotineiras e, ainda, de que é preciso para que o sujeito seja visto pela suas realizações e não por sua deficiência, ou seja, é necessário que ele tenha de fazer coisas extraordinárias, heroicas.

Para mais, a imbricação de enunciados como Yes, I can [...] do anything [...] go all the way [...], com imagens de atletas e não atletas realizando atividades como descer escadas em cadeira de rodas, pilotando aviões, dirigindo carros de corrida, bem como, trabalhando felizes em escritórios, presidindo reuniões de empresas etc., produz como efeito de sentido a ideia de que cabe à pessoa com deficiência, e apenas a ela, a responsabilidade por sua inclusão (ou exclusão). Dessa forma, não há necessidade de intervenção do Estado.

Face ao exposto, podemos deduzir que o filme atualiza, enquanto memória discursiva, a ideia de que o corpo com deficiência é um corpo que deve ser olhado, tal qual as feiras teratológicas do início do século XX, uma vez que as tomadas de câmera ao longo de todo o filme dão protagonismo ao corpo com deficiência, e não às práticas executadas, sejam esportivas ou não. Nesse sentido, o filme significa e reduz as pessoas com deficiência a um aspecto do seu corpo, evidenciando-o como diferente, anormal.

\section{REFERÊNCIAS}

BARBAI, Marcos Aurélio. Arte e Deficiência: mãos para que te quero se tenho boca e pé para pintar. In: COSTA, Greciely Cristina da; CHIARETTI, Paula (org.). Arte e diversidade. Trilogia travessia da diversidade. Campinas, SP: Pontes Editores, 2016. v. 3.

COSTA, Greciely Cristina da. Discursividades de inclusão e a manutenção da exclusão. In: FERREIRA, Eliana Lucia; ORLANDI, Eni. P. Discursos sobre a inclusão. Niterói: Intertexto, 2014.

COURTINE, Jean-Jacques. O corpo anormal: história e antropologia culturais da deformidade. In: COURTINE, Jean-Jacques; VIGARELLO, Georges. História do corpo: as mutações do olhar: o século XX. 4. ed. Petrópolis, RJ: Vozes, 2011.

FIGUEIREDO, T. Os atletas para(o)límpicos na imprensa: análise comparativa da cobertura noticiosa das mídias no Brasil e em Portugal de 1996-2008. Porto: T. Figueiredo. Dissertação (Mestrado em Ciências da Comunicação) - FLUP, 2010.

HASHIGUTI, Simone Tiemi. Corpos e formas (in)visíveis: entre a regularização e a ruptura de sentidos. In: COSTA, Greciely Cristina da; CHIARETTI, Paula (org.). Arte e diversidade. Trilogia travessia da diversidade. Campinas, SP: Pontes Editores, 2016. v. 3 . 
HASHIGUTI, Simone Tiemi. Corpo de memória. Jundiaí: Paco Editorial, 2015.

LAGAZZI, Suzy. O sangue na cor das letras. O agudo no tom da voz. A resistência na imprevisibilidade das derivas. In: SOUSA, L. Abrahão e; ISHIMOTO, A; DARÓZ, E; GARCIA D. (org.). Resistirmos, a que será que se destina? São Carlos: Pedro \& João, 2018.

LAGAZZI, Suzy. Em torno da prática discursiva materialista. Organon, Porto Alegre, v. 30, n. 59, p. 85-100, jul/dez. 2015.

LAGAZZI, Suzy. Metaforizações metonímicas do social. REDISCO: UESB, v. 2, n. 1, jan./jun. 2013.

ORLANDI, Eni. P. Discurso e texto: formulação e circulação dos sentidos. 4. ed, Campinas, SP: Pontes Editores, 2012.

ORLANDI, Eni P. Ser diferente é ser diferente: a quem interessam as minorias? In: ORLANDI, Eni. P. Linguagem, sociedade, políticas. Pouso Alegre: UNIVÁS; Campinas: RG Editores, 2014.

ORLANDI, Eni P. Discurso em análise: sujeito, sentido e ideologia. 3. ed. Campinas, SP: Pontes Editores, 2016.

PÊCHEUX, Michel. O discurso: estrutura ou acontecimento. 7. ed. Campinas, SP: Pontes Editores, 2015.

PÊCHEUX, Michel. Semântica e discurso: uma crítica à afirmação do óbvio. Tradução de Eni Orlandi et al. 2.ed. Campinas, SP: Editora da Unicamp, 2014.

PEPPER, Penny. Turning Paralympian into 'superhumans' is no help to disabled people. Disponível em https://www.theguardian.com/commentisfree/2016/sep/06/paralympianssuperhumans-disabled-people. Acesso: em 7 nov. 2019.

VIGARELLO, Georges. Estádio: o espetáculo esportivo das arquibancadas às telas. In: COURTINE, Jean-Jacques; VIGARELLO, Georges. História do corpo: as mutações do olhar: o século XX. 4. ed. Petrópolis, RJ: Vozes, 2011.

Artigo recebido em: nov. de 2019.

Aprovado e revisado em: abr. de 2020.

Publicado em: julho de 2020.

Para citar este texto:

LIMA, Clevisvaldo Pinheiro. Ter Deficiência é Ser Super-Humano? Uma análise discursiva de um filme publicitário para as paralimpíadas Rio 2016, "We're the superhumans". Entremeios [Revista de Estudos do Discurso, ISSN 2179-3514, on-line, www.entremeios.inf.br], Seção Estudos, Programa de Pós-Graduação em Ciências da Linguagem (PPGCL), Universidade do Vale do Sapucaí (UNIVÁS), Pouso Alegre (MG), vol. 21, p. 134-148, jan. - jun. 2020.

DOI: http://dx.doi.org/10.20337/ISSN2179-3514revistaENTREMEIOSvol21pagina134a148 